\title{
Editorial
}

\section{Grad + e a Consolidação de um Espaço Plural Devotado ao Ensino de Graduação}

\author{
Prof. Thiago Mio Salla e Prof. Eder Cassola Molina
}

Em vias de completar um ano de existência, a Revista de Graduação da USP (também conhecida apenas por sua logomarca $\mathrm{Grad}+$ ) chega a seu terceiro número. Com ele, a publicação dá mais um passo firme no sentido de consolidar-se como um fórum de reflexões, debates e compartilhamento de experiências em torno do ensino de graduação. Se somarmos as colaborações até o momento estampadas em suas páginas, o periódico já ultrapassou a marca de cinquenta textos, que abarcam um conjunto multifacetado de temas e abordagens, entre os quais se podem elencar: metodologias ativas de ensino-aprendizagem; uso de tecnologias como recurso didático; relato de experiências bem-sucedidas em sala de aula; elaboração, aplicação e avaliação de materiais didáticos; apresentação e análise de trabalhos de reestruturação curricular; enfim, manifestações claras do engajamento docente na busca por métodos, técnicas, práticas e estruturas que promovam o magistério de maneira qualificada e moderna em cursos de graduação das mais diferentes áreas do saber.

Confirmando tais diretrizes conceituais, a presente edição de Grad+, não por acaso, prima pela pluralidade. No que diz respeito às colaborações que particularizam metodologias ativas de ensino-aprendizagem, destaque para uma iniciativa de Geografia da FFLCH/USP que utiliza as aulas laboratoriais como meio de, partindo de um campo de conhecimento específico, articular diferentes saberes com o objetivo de promover uma visão mais complexa e global do pensamento científico, de modo a favorecer a formação de sujeitos dialógicos e críticos. Do Instituto de Relações Internacionais da USP, oferecemos ao leitor um artigo que se propõe a avaliar, em chave comparatista, o uso da simulação como instrumento pedagógico no ensino de estratégias, perfis, posturas e ações relativas à área de Negociações. Tal procedimento se dá por meio da aplicação de um jogo em que duas equipes, ao longo de oito rodadas, negociam o preço de um barril de petróleo e, em seguida, opera-se a avaliação dos ganhos pedagógicos da iniciativa em termos práticos e teóricos.

Da Escola de Artes, Ciências e Humanidades da Universidade de São Paulo, vem uma proposta que, a um só tempo, questiona o ensino tradicional de Anatomia Humana baseado na memorização e na utilização de cadáveres, e apresenta estratégias alternativas que procuram implementar uma abordagem interdisciplinar e humanizada, com privilégio para as experiências e corpos dos próprios discentes. Tal orientação se propõe ainda a retirar o estudante de uma postura passiva e a elevá-lo à condição de protagonista de seu próprio aprendizado. De modo análogo, da Escola Politécnica, ganha relevo uma experiência de ensino-aprendizagem baseada em projetos que não só tira os alunos da condição de espectadores como os aproxima da realidade e das experiências do mercado de trabalho. Mais especificamente, ao longo do semestre, cabe-lhes atuar tais como consultores e realizar o diagnóstico energético de suas residências, analisar os dados e então propor mudanças de hábitos de consumo e troca de dispositivos, sempre levando em consideração a eficiência no uso da energia, os custos envolvidos e os impactos ambientais das escolhas realizadas.

Como tem se tornado tradição ao longo dos últimos números, as páginas de Grad + abrem generoso espaço para inovações implementadas em disciplinas de graduação. Destaque inicial para os docentes da Faculdade de Medicina de Ribeirão Preto que vêm empregando com sucesso uma plataforma educacional interativa voltada ao ensino de atendimento a pacientes vítimas de traumas. Em termos metodológicos, a 
iniciativa alia estudo de caso, blended learning (mescla de ensino a distância e presencial, com atividades em tempo real e/ou em diferentes tempos) e o conceito de sala de aula invertida (com ênfase no protagonismo dos discentes e no uso do tempo presencial da aula para a realização de desafios locais e globais).

Nessa mesma linha pautada pela inovação, do curso de Nutrição da Universidade Federal do Tocantins, apresenta-se um estudo a respeito da utilização de um blog educativo destinado ao ensino de Bioquímica. Da graduação em Editoração da Escola de Comunicações e Artes da USP, ressalta-se uma iniciativa de trabalhar com o e-book em sala de aula em perspectiva transdisciplinar. Todavia, para além do trabalho em sala de aula com as novas possibilidades abertas pelas Tecnologias de Informação e Comunicação, há que se salientar também a inventividade docente. Em experiência desenvolvida no curso de Medicina Veterinária da USP de Pirassununga, foram produzidos simuladores artesanais (a partir da utilização de materiais de baixo custo e fácil acesso) empregados no ensino de ultrassonografia. Além da evidente vantagem econômica, a iniciativa permitiu o incremento no aprendizado de diferentes habilidades por parte dos alunos.

Entre as ferramentas didáticas dinamizadoras do ensino-aprendizagem, vem da Licenciatura em Geociências e Educação Ambiental, do Instituto de Geociências da USP, uma iniciativa que sobressai pelo uso do mapeamento socioambiental (levantamento de informações sobre um lugar/ambiente específico que se converte em conhecimento mediante a confecção de mapas) como meio de diagnosticar uma determinada realidade local, bem como de planejar e executar ações que visem à melhoria da qualidade de quem se insere em tal espaço. Nesse sentido, tal abordagem participativa e interdisciplinar procura estabelecer uma ponte entre o científico e o cotidiano, de modo a enriquecer a formação de futuros docentes.

De maneira análoga, da Faculdade de Odontologia de Bauru, temos o uso de uma Maquete de Máquina de Ensaio Universal (instrumento por meio do qual se realizam inúmeros testes das propriedades mecânicas de um determinado item) como forma de tornar inteligíveis conceitos a priori essencialmente teóricos a respeito da especificidade constitutiva de materiais dentários. Da Faculdade de Educação da USP, por sua vez, distingue-se um relato que trata do uso do portfólio como ferramenta avaliativa capaz de contribuir para a reflexão do estudante sobre o seu próprio processo de aprendizagem, bem como para a ruptura da lógica classificatória de verificação da assimilação de conteúdos. Da Escola Superior de Agricultura "Luiz de Queiroz", apresentamos um relato que discorre sobre a utilização de artigos científicos como recurso didático (leitura, interpretação e análise particularizada). Tal estratégia, além de estimular o pensamento crítico, permitiu que os alunos aprimorassem seu domínio da linguagem científica e sua autonomia.

Neste número, uma vez mais abrimos espaço para educação tutorial (PET), prática pedagógica cada vez mais utilizada por diferentes instituições de Ensino Superior com vistas a incrementar o ensino de graduação em perspectiva a um só tempo coletiva e crítica. Mais especificamente, apresenta-se aqui um trabalho que procurou avaliar os resultados positivos decorrentes da flexibilização das normas de entrada e de permanência em grupos PET da Unesp de Rio Claro. Paralelamente, da Escola de Artes, Ciências e Humanidades da USP, temos ainda o relato de uma experiência de tutoria de estudantes de graduação, em disciplinas voltadas para resolução de problemas que têm como base os princípios do PBL (Problem-based Learning). Tal estudo evidenciou que essa metodologia colaboraria, entre outros aspectos, para a construção coletiva do conhecimento e para maior autonomia do estudante.

Entre os relatos de experiência docente recolhidos neste terceiro número de Grad+, ofertamos ao leitor uma contribuição oriunda da Escola Bahiana de Medicina e Saúde Pública (EBMSP) que aborda o modo por meio do qual tal instituição, considerando a importância cada vez maior do papel dos exames de imagem na investigação diagnóstica, implementou estratégias pedagógicas voltadas ao ensino de Anatomia Radiológica. Mediante esse procedimento, a EBMSP pretendeu ajustar sua matriz curricular às deman- 
das profissionais e, a um só tempo, potencializar a formação acadêmica e o aprendizado do aluno. Da Escola de Comunicações e Artes da USP, em esforço de caráter memorialístico, advém uma colaboração que procurou ouvir professores, ex-alunos e colaboradores com o objetivo de traçar o percurso histórico do ensino de Radiojornalismo na referida instituição, além de, em seguida, apresentar a metodologia e a estrutura das disciplinas hoje dedicadas a tal área da Comunicação. Do Centro de Práticas Esportivas da USP, destaca-se o relato sobre um curso voltado ao ensino de Remo que buscava enfatizar não apenas a prática da modalidade, mas também a prática do ensino de tal esporte, de maneira a ressaltar a importância da experiência concreta como meio fundamental para o entendimento quer da aprendizagem, quer do magistério. Do Instituto de Biociências da USP, selecionamos um texto que trata da realização de estágio supervisionado no âmbito da Licenciatura em Ciências Biológicas. Para além do simples cumprimento das horas exigidas, salienta-se a promoção de práticas de intervenção quer baseadas no ensino por investigação, quer acompanhadas de exercício de pesquisa na área de educação científica.

Assim como nos números anteriores, Grad+ também confere espaço a textos voltados a apresentar e a avaliar processos de (re)estruturação de cursos de graduação. Da Faculdade de Odontologia de Bauru, avulta o estudo a respeito do projeto político-pedagógico (PPP) do curso de Fonoaudiologia lá oferecido. Mediante tal esforço investigativo, os autores procuraram analisar, sobretudo, se o referido documento refletiria o perfil de egresso pretendido. Trata-se de um trabalho abrangente, cujas premissas e metodologia podem ser replicadas em outros contextos. Nessa mesma linha, da Escola de Comunicações e Artes, apresenta-se um relato que descreve o processo democrático de reformulação do PPP e as bases da nova estrutura curricular da graduação em Editoração. Do Instituto de Matemática e Estatística, temos a descrição de todo o trabalho coletivo que se fez presente na última reestruturação da grade do Bacharelado em Ciência da Computação.

Por fim, quanto à produção de materiais didáticos, não podemos deixar de chamar a atenção (vide a capa deste número) para uma iniciativa do Instituto de Astronomia, Geofísica e Ciências Atmosféricas da USP voltada à produção de história em quadrinhos e de filmes de animação. Se, por um lado, tal trabalho procura se valer do fascínio da população pelos astros para promover a divulgação, em linguagem acessível, de conceitos básicos referentes às ciências fundamentais, por outro, repercute positivamente no âmbito da graduação como estratégia para diminuir a evasão e estimular a conclusão do curso no tempo ideal.

Percorrido esse imenso e pulsante manancial de colaborações provenientes dos mais diferentes campos do saber e das mais variadas faculdades, escolas e institutos, fica apenas a certeza de que nossa viagem editorial não termina por aqui. O próximo número já está em andamento, e, com ele, esperamos celebrar o primeiro aniversário da revista e, assim, dar mais um passo no sentido de consolidar este espaço devotado ao ensino de graduação e à valorização da atividade docente. Sendo assim, que venha a Grad $+4 .$. 